\title{
Effect of vitamin D supplementation on fasting plasma glucose, insulin resistance and prevention of type 2 diabetes mellitus in non-diabetics: A systematic review and meta-analysis
}

\author{
SITIAN HE ${ }^{1}$, SONGCHENG YU ${ }^{1}$, ZONGLEI ZHOU ${ }^{1}, \mathrm{CHONGJAN} \mathrm{WANG}^{2}$, YONGJUN WU ${ }^{1}$ and WENJIE $\mathrm{LI}^{3}$ \\ Departments of ${ }^{1}$ Sanitary Chemistry, ${ }^{2}$ Epidemiology and Statistics, and ${ }^{3}$ Nutrition and Food Hygiene, \\ College of Public Health, Zhengzhou University, Zhengzhou, Henan 450001, P.R. China
}

Received November 7, 2017; Accepted February 6, 2018

DOI: $10.3892 /$ br.2018.1074

\begin{abstract}
Increasing epidemiological studies suggest that there is an association between vitamin $\mathrm{D}$ deficiency and risk of type 2 diabetes mellitus (T2DM). Therefore, randomized clinical trials (RCTs) have been performed to observe the effect of vitamin D supplementation on preventing T2DM, decreasing fasting plasma glucose (FPG) and improving insulin resistance to confirm the association between vitamin D and T2DM. However, the results of RCTs on controlling FPG level, improving insulin resistance and preventing T2DM in non-diabetics are inconsistent. In the present study, a systematic meta-analysis considering individual variation and intervention strategy was conducted to establish an objective and definitive conclusion. The results suggested that vitamin D supplementation had no significant effect on controlling FPG level, improving insulin resistance or preventing T2DM in non-diabetics in a pooled meta-analysis of 23 articles (containing 28 RCTs). However, stratified analysis indicated that supplementation of vitamin D had differential effects on FPG control, insulin sensitivity improvement and T2DM prevention in individuals with different baseline states: FPG was decreased for those with BMI $<25(\mathrm{P}=0.048)$ or $20 \leq 25(\mathrm{OH}) \mathrm{D}<30 \mathrm{ng} / \mathrm{ml}(\mathrm{P}=0.002)$; insulin resistance was improved for those with $25(\mathrm{OH}) \mathrm{D} \geq 30 \mathrm{ng} / \mathrm{ml}(\mathrm{P}=0.021)$; and
\end{abstract}

Correspondence to: Mr. Songcheng Yu, Department of Sanitary Chemistry, College of Public Health, Zhengzhou University, 100 Kexue Avenue, Zhengzhou, Henan 450001, P.R. China

E-mail: scyu@zzu.edu.cn

Abbreviations: T2DM, type 2 diabetes mellitus; 25(OH)D, 25-hydroxyvitamin D; RCT, randomized clinical trial; FPG, fasting plasma glucose; HOMA-IR, homeostasis model insulin resistance index; BMI, body mass index; SD, standard deviation; CI, confidence interval; RR, relative risk; MD, mean difference; SMD, standardized mean difference; WMD, weighted mean difference; ITT, intention-to-treat

Key words: vitamin D, type 2 diabetes mellitus, fasting plasma glucose, insulin resistance, meta-analysis risk of T2DM was lower for pre-diabetic individuals $(\mathrm{P}=0.047)$ or for those with $25 \leq \mathrm{BMI}<30(\mathrm{P}=0.032)$. Additionally, the effect on T2DM prevention was improved when the supplement dose was $>2,000 \mathrm{IU} /$ day $(\mathrm{P}=0.047)$ and with intervention without calcium $(\mathrm{P}=0.047)$. Thus, further trials should focus on individual baselines and the supplementation strategy of vitamin $\mathrm{D}$ in the prevention of T2DM.

\section{Introduction}

The function of vitamin D \{25-hydroxyvitamin D [25(OH)D]\} in regulating calcium homeostasis and bone metabolism was first identified in 1930 and has since become well established (1). Over recent decades, increasing data has implicated vitamin D to be a type of endocrine substance that serves an important role in many biological activities, including the immune response and cell differentiation, proliferation and apoptosis (2). Abnormal vitamin $\mathrm{D}$ level may be a risk factor for a range of acute and chronic illnesses, including cancer, diabetes and cardiovascular diseases $(3,4)$.

Previous epidemiological studies have indicated an association between vitamin D deficiency and risk of type 2 diabetes mellitus (T2DM) (5,6). Animal studies have also demonstrated that vitamin D may serve a role in insulin secretion $(2,7)$. These findings suggested that vitamin D deficiency probably has a causal relationship with T2DM. Therefore, randomized clinical trials (RCTs) were needed to observe the effect of vitamin D supplementation on prevention of T2DM, decreasing fasting plasma glucose (FPG) and/or improvement of insulin resistance, to confirm the association between vitamin D and T2DM.

Numerous RCTs of vitamin D supplementation have been performed in the past decade. The results regarding control of FPG level, improving insulin resistance and preventing T2DM were inconsistent. A number of RCTs suggested that supplementation of vitamin $\mathrm{D}$ could improve insulin resistance and FPG (8-11). However, certain studies obtained contrary results (12) or identified no beneficial effect (13-16). Dutta et al revealed that vitamin D supplementation could significantly lower the progression of diabetes (17); while reports from others indicated that supplementation with vitamin D had no effect on T2DM prevention $(13,18,19)$. Thus, a meta-analysis is 
required to validate the effect of vitamin $\mathrm{D}$ supplementation on diabetes development.

A number of meta-analyses on the effect of vitamin D supplementation on FPG control have been conducted. These mainly focused on glycemic control in T2DM patients $(20,21)$, glucose metabolism in gestational diabetes patients (22), and glycemic control and insulin resistance in non-T2DM individuals (23). However, these analyses did not consider the preventative effect of vitamin D on T2DM. Furthermore, the impacts from individual variation and intervention strategy were not considered. Previous studies have suggested that there is individual variation for vitamin D sensitivity, with different individuals exhibiting different responses to the same vitamin D supplementation $(24,25)$. Considering the aforementioned reasons, the present aim was to conduct a systematic update meta-analysis, in order to obtain an objective and more definitive conclusion on the effect of vitamin D supplementation on FPG, insulin resistance and prevention of T2DM for non-T2DM people. This should provide insight on the relationship between vitamin D deficiency and risk of T2DM, as well as how vitamin D serves a role in T2DM development.

\section{Materials and methods}

Literature retrieval. RCT literature on the effects of vitamin D supplementation on FPG, insulin resistance and risk of T2DM in non-diabetic individuals published from January 2000 to February 2017 was retrieved from PubMed (https://www. ncbi.nlm.nih.gov/pubmed/) and two Chinese academic databases, CNKI (http://www.cnki.net) and Wanfang (http://www. wanfangdata.com.cn/index.html). The language of the literature was restricted to English and Chinese. The key words used to search relevant articles were 'vitamin $\mathrm{D}$ ', 'vitamin $\mathrm{D}_{2}$ ', 'vitamin $\mathrm{D}_{3}$, ' 'ergocalciferol', 'cholecalciferol', 'calciferol', 'vitamin D analogs', '25-(OH)D', '1,25- $(\mathrm{OH})_{2} \mathrm{D}$ ', 'diabetes mellitus', 'type 2 diabetes mellitus', 'hyperglycemia', 'impaired glucose tolerance', 'insulin resistance' and 'insulin sensitivity'.

Literature screening. The inclusion criteria were as follows: i) Study subjects were non-diabetic individuals, including those with normal blood glucose $(<6.1 \mathrm{mmol} / \mathrm{l})$ and prediabetes $(6.1-7.0 \mathrm{mmol} / \mathrm{l})(26)$; ii) RCTs that focused on the influence of vitamin D deficiency on the indices related to blood glucose through vitamin D supplementation; iii) the intervention group vs. control group should be vitamin D vs. placebo, vitamin $\mathrm{D}+$ calcium vs. placebo + calcium or vitamin D + calcium vs. placebo; and iv) study outcome indicators included at least one of the following: Incidence rate or the number of participants who developed T2D, FPG measurements and/or homeostasis model insulin resistance index (HOMA-IR) data, with the value for FPG and HOMA-IR prior to and following supplementation expressed as the mean \pm standard deviation (SD).

The exclusion criteria were as follows: i) Animal experiments; ii) non-RCTs; iii) incomplete information on the outcome indicators, such as only reporting the mean and not providing SD; iv) outcome variables were expressed as the median (four interquartile range) or interquartile range, and outcome measurements that did not meet the inclusion requirements; v) articles that were reviews, systematic reviews or meta-analyses; and vi) the subjects were children, pregnant women or lactating women, or suffering from any diseases.

Data extraction. Literature screening and data extraction were performed by two reviewers. The quality and bias risk of the included studies were evaluated. Disputes or differences in the process of document selection or data extraction were settled by a third reviewer. The extracted data included: i) Title, first author and year of publication; ii) geographic location, sample size, blood glucose status, age, body mass index (BMI), baseline $25(\mathrm{OH}) \mathrm{D}$ concentration, female proportion and follow-up time; iii) dose and methods of vitamin D supplementation; iv) the related data of outcome variables; and v) the information needed for bias risk assessment and Jadad scoring.

Bias risk and quality evaluation of included studies. The bias risk assessment tool recommended by the Cochrane Handbook for Systematic Reviews of Interventions, version 5.1.0 (27) and the Jadad scoring scale (28) were used to assess the methodological quality of the included RCTs. The evaluation criteria in the bias risk assessment include: i) Randomization methods; ii) allocation concealment; iii) whether the researchers, participants and observers remained blinded; iv) the integrity of data; v) whether there was selective reporting bias; and vi) other sources of bias. In the Jadad scoring scale, there are three levels for the randomization method, allocation concealment and blinding method, namely appropriate (2 points), unclear (1 point) and inappropriate ( 0 point). In addition, the scale accounts for when reasons for withdrawal of subjects are reported (1 point) or unspecified ( 0 points). Studies that scored $\leq 4$ points were considered to be of high quality.

Data synthesis. When the literature provided the mean $\pm \mathrm{SD}$ of FPG and/or HOMA-IR at baseline and at the end of the study, mean \pm SD changes in corresponding outcome variable were converted by the following formula: $\mathrm{MD}_{\Delta}=\mathrm{Mean}_{1}-\mathrm{Mean}_{0}$; and $\mathrm{SD}_{\Delta}=\left(\mathrm{SD}_{1}^{2}+\mathrm{SD}_{0}{ }^{2}-2 \times 0.5 \mathrm{xD}_{1} \times \mathrm{SD}_{0}\right)^{1 / 2}$, where Mean ${ }_{1}$, mean of outcome variable after intervention; $\mathrm{SD}_{0}, \mathrm{SD}$ of outcome variable after intervention; $\mathrm{Mean}_{0}$, mean of outcome variable at baseline; $\mathrm{SD}_{0}, \mathrm{SD}$ of outcome variable at baseline (29). The standard error with $95 \%$ confidence intervals (95\% CIs) of the change in the corresponding outcome variable was converted by the following formula: $\mathrm{SE}_{\Delta}=\left(\mathrm{UL}_{\Delta}-\mathrm{LL}_{\Delta}\right) / 3.92$, where $\mathrm{SE}_{\Delta}$, the standard error of the change in the corresponding outcome variable; $\mathrm{UL}_{\Delta}$, the upper limit of the $95 \% \mathrm{CI} ; \mathrm{LL}_{\Delta}$, the lower limit of the $95 \% \mathrm{CI}$. The results expressed as standard error were then transformed into SD by the following formula: $\mathrm{SD}=\sqrt{ } \mathrm{n} \times \sigma$, where $\mathrm{n}$, sample size; $\sigma$, standard error. The unified units of FPG, baseline $25(\mathrm{OH}) \mathrm{D}$ concentration and vitamin $\mathrm{D}$ intervention dose were $\mathrm{mg} / \mathrm{dl}, \mathrm{ng} / \mathrm{ml}$ and IU, respectively (with $1 \mathrm{mg} / \mathrm{dl}=18 \mathrm{mmol} / \mathrm{l}$, $1 \mathrm{ng} / \mathrm{ml}=2.5 \mathrm{nmol} / 1$ and $1 \mu \mathrm{g}=40 \mathrm{IU}$ ). The association between vitamin $\mathrm{D}$ supplementation and T2DM was expressed by relative risk ( $R R=$ incidence of supplementation group/incidence of control group), and the effect on FPG was represented by mean difference (MD = glucose level pre-supplementation - glucose level following supplementation). The effect on insulin resistance (HOMA-IR) was represented by standardized mean difference (SMD = difference of HOMA-IR/SD of HOMA-IR) as the measurement method, or when units were inconsistent. Subgroup analysis was performed in view of the differences 


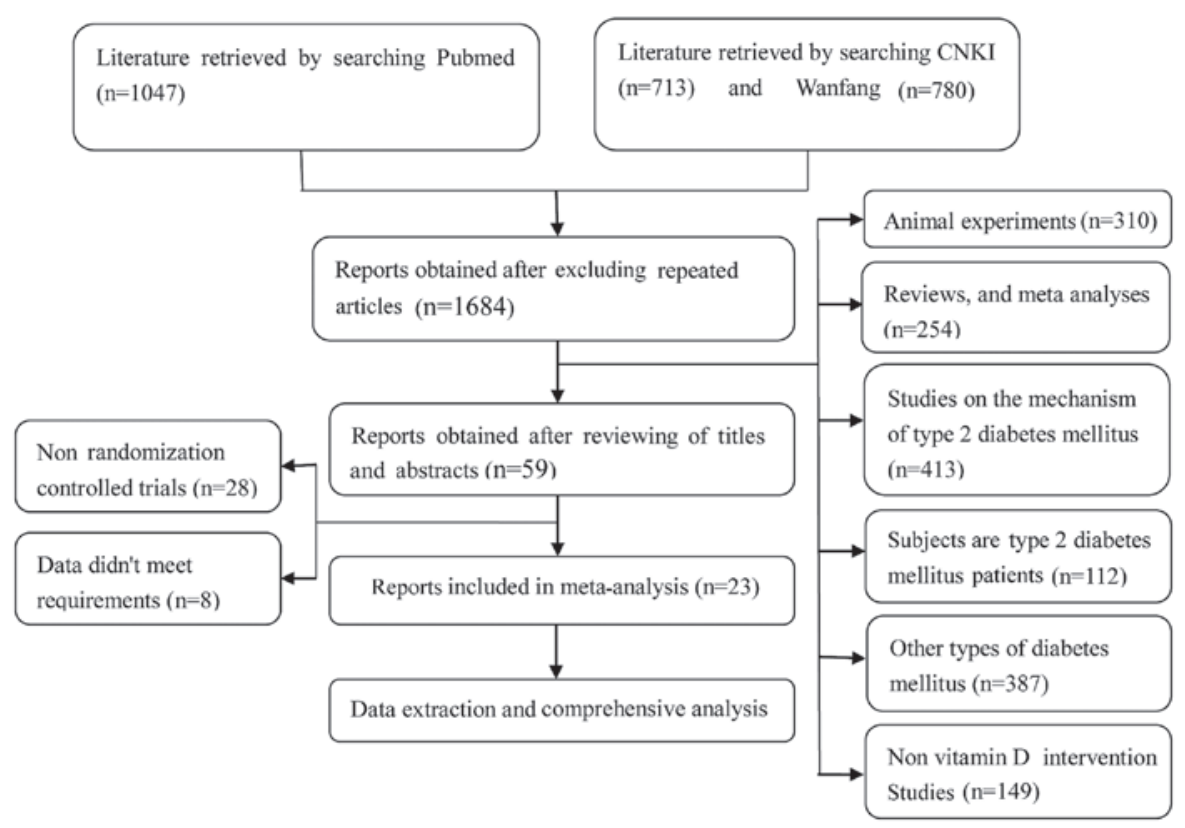

Figure 1. Flow chart of literature screening process. A total of 1,684 literatures were retrieved following exclusion of the repeated reports. Of these, 23 articles were included in the meta-analysis according to the inclusion and exclusion criteria.

of research aims and interventions among studies. Subgroups were stratified on the following bases: i) Glucose status of subjects: Normal glucose tolerance or prediabetes; ii) the age of subjects: Age $<45$ years, $45 \leq$ age $<60$ years, age $\geq 60$ years; iii) the body weight index of subjects: Normal (BMI $<25$ ), overweight $(25 \leq \mathrm{BMI}<30)$ and obese (BMI $\geq 30)(30)$; iv) the baseline $25(\mathrm{OH}) \mathrm{D}$ concentration of subjects: Deficient $[25(\mathrm{OH}) \mathrm{D}$ $<20 \mathrm{ng} / \mathrm{ml}$ ], insufficient [ $20 \leq 25(\mathrm{OH}) \mathrm{D}<30 \mathrm{ng} / \mathrm{ml}]$ and sufficient $[25(\mathrm{OH}) \mathrm{D} \geq 30 \mathrm{ng} / \mathrm{ml}](31) ; \mathrm{v})$ the follow-up time: $<12$ months or $\geq 12$ months; vi) vitamin D intervention dose: $\leq 2,000 \mathrm{IU} /$ day or $>2,000 \mathrm{IU} /$ day; vii) intervention with Ca or not; and viii) Jadad score: $<4$ points or $\geq 4$ points.

Statistical analysis. Stata software (version 12.0; StataCorp LP, College Station, TX, USA) was used to analyze the population data. The statistical heterogeneity was estimated by $Q$ test $(\alpha=0.1)$ and from the inhibition coefficient $\left(\mathrm{I}^{2}\right)$. If there was no statistical heterogeneity among studies, the fixed effect model was used for analysis; otherwise the random effect model was applied to analyze data on the premise of excluding clinical heterogeneity and methodological heterogeneity if statistical heterogeneity existed (27). In addition, the source of heterogeneity was investigated by subgroup analysis. Publication bias was assessed by using funnel plots, Egger's test and Begg's test (32). $\mathrm{P}<0.05$ was considered to indicate statistical significance.

\section{Results}

Literature retrieval. A total of 1,047 articles in English and 1,493 articles in Chinese were retrieved in accordance with the search words established in advance. Of these, 47 English articles and 12 Chinese articles were retained following the exclusion of repeated literature and after reading the abstracts. Finally, a total of 23 articles (8-19,33-43), including 22 English articles and 1 Chinese publication, were included for meta-analysis after reading the full text according to the inclusion and exclusion criteria. The full literature retrieval process is outlined in Fig. 1.

Characteristics and bias risk assessment of included studies. A total of 28 RCTs from 23 studies were included in the current meta-analysis. Among these studies, the Jadad scores of 16 studies (containing 21 RCTs) were $\geq 4$ points. The basic characteristics of the studies are summarized in Table I. A total of 17 studies (containing $20 \mathrm{RCTs}$ ) reported the methods of generating random allocation sequences, including computer-generated random number sequences and stratified randomization sets. A total of 11 studies (containing 13 RCTs) reported the methods of concealment allocation, including central or pharmacy control, distribution, opaque containers or sealed envelopes. A double-blinded method was adopted in 20 studies (containing 25 RCTs). A total of 19 studies (containing 24 RCTs) described the number and causes of those lost to follow-up. A total of 5 studies (containing 7 RCTs) were analyzed using the intention-to-treat (ITT) method (Table I).

Effect of vitamin D supplementation on FPG. A total of 21 studies $(8,10-19,33,35-43)$ containing 26 RCTs reported FPG results. There was statistical heterogeneity between the studies $\left(\mathrm{I}^{2}=89.9 \%, \mathrm{P}<0.001\right)$. Subsequently, the random effect model was used for analysis. The results indicated that FPG following vitamin D intervention did not significantly decrease compared with control $(\mathrm{MD}=-1.76$; 95\% $\mathrm{CI}=-4.07$, 0.55, P=0.135; Fig. 2). Subgroup analysis revealed that FPG levels in pre-diabetic individuals and in those whose BMI $<25$ with vitamin D supplementation were significantly lower than those of controls $(\mathrm{MD}=-3.40 ; 95 \% \mathrm{CI}=-6.64,-0.15, \mathrm{P}=0.041$ and $\mathrm{MD}=-2.80,95 \% \mathrm{CI}=-5.57,-0.03, \mathrm{P}=0.048$, respectively; Table II). In the subgroup of baseline $25(\mathrm{OH}) \mathrm{D}_{3}$ insufficiency $[20 \leq 25(\mathrm{OH}) \mathrm{D}<30 \mathrm{ng} / \mathrm{ml})]$, the level of FPG following 


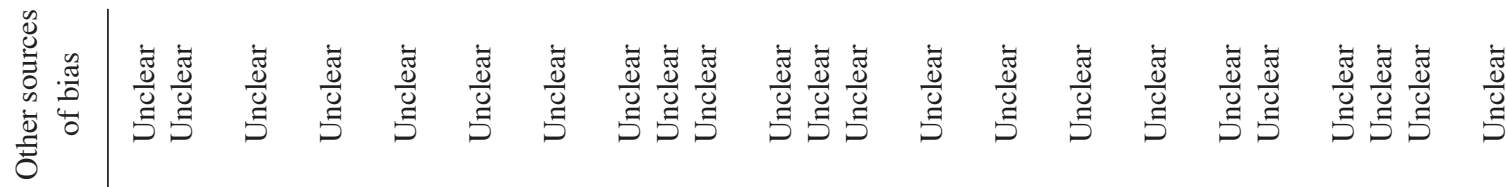
总兽

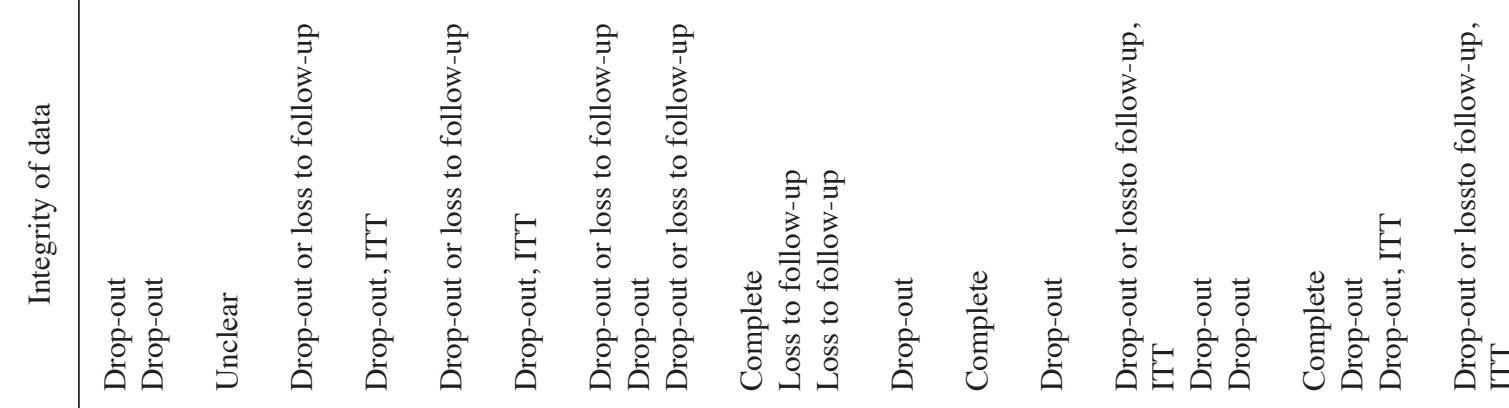

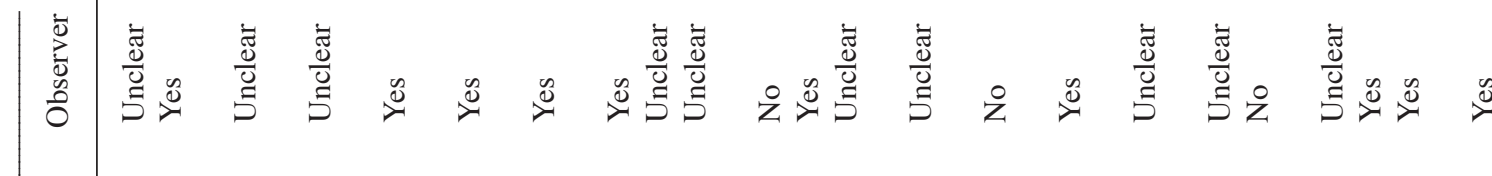

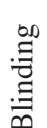

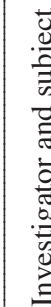

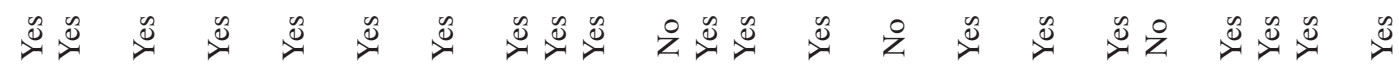




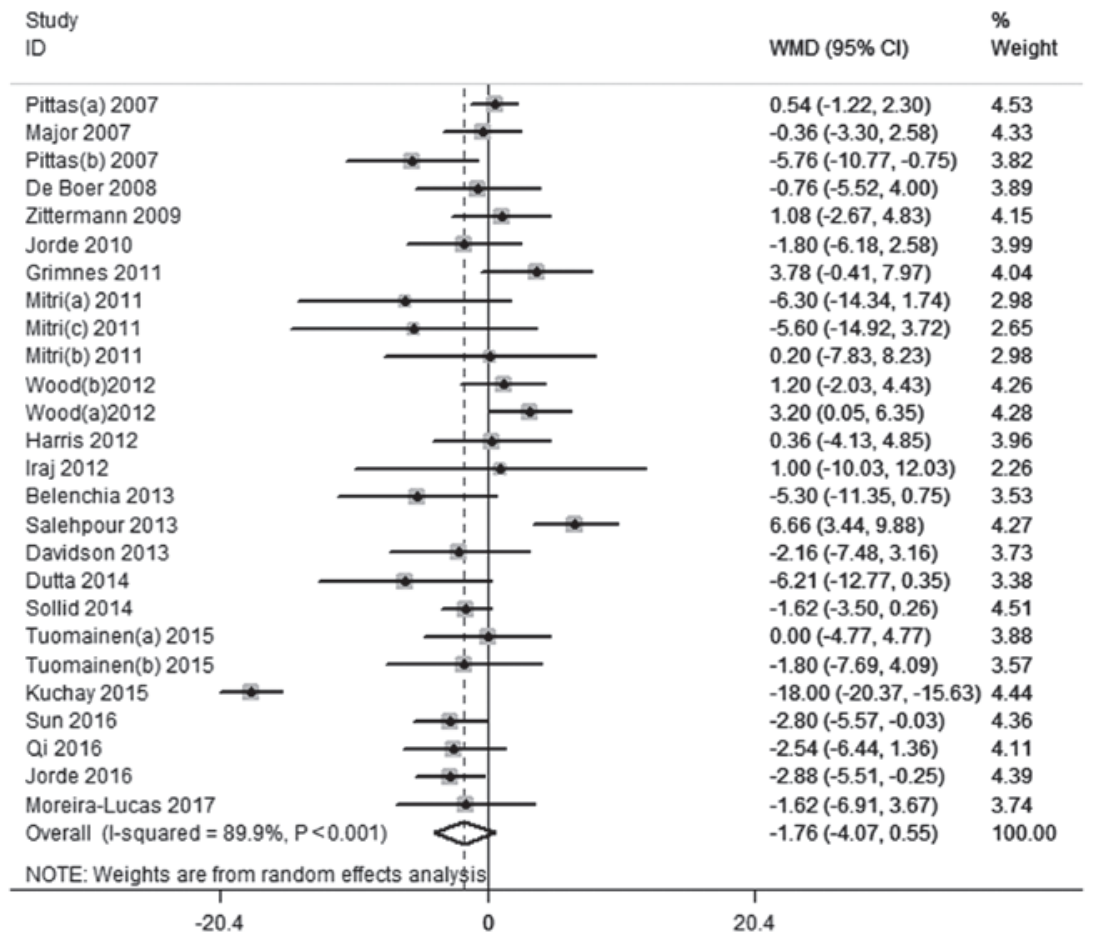

Figure 2. Forest plot of vitamin D supplementation effect on FPG. The pooled results suggested that there was no statistically significant difference in FPG levels in non-diabetics following vitamin D intervention or control treatments. FPG, fasting plasma glucose; WMD, weighted mean difference; $95 \%$ CI, $95 \%$ confidence interval. (a), (b) and (c) indicate the first, second and third trial in the reference, respectively.

\begin{tabular}{|c|c|c|}
\hline Study & & $\%$ \\
\hline ID & $\operatorname{SMD}(95 \% \mathrm{Cl})$ & Weight \\
\hline Pittas(b) 2007 & $-0.49(-0.90,-0.07)$ & 6.27 \\
\hline De Boer 2008 & $0.05(-0.16,0.27)$ & 24.16 \\
\hline Nagpal 2009 & $-0.02(-0.49,0.44)$ & 4.99 \\
\hline Jorde 2010 & $-0.16(-0.65,0.32)$ & 4.54 \\
\hline Grimnes 2011 & $0.11(-0.30,0.51)$ & 6.58 \\
\hline Iraj 2012 & $0.00(-0.62,0.62)$ & 2.81 \\
\hline Harris 2012 & $0.16(-0.26,0.58)$ & 6.23 \\
\hline Wood(a)2012 & $0.08(-0.31,0.47)$ & 7.13 \\
\hline Wood(b)2012 & $-0.03(-0.42,0.36)$ & 7.14 \\
\hline Salehpour 2013 & $-0.13(-0.58,0.31)$ & 5.40 \\
\hline Belenchia 2013 & $-0.73(-1.41,-0.04)$ & 2.30 \\
\hline Davidson 2013 & $-0.04(-0.41,0.34)$ & 7.65 \\
\hline Oosterwerff 2014 & $0.09(-0.25,0.43)$ & 9.12 \\
\hline Sun 2016 & $-0.02(-0.46,0.41)$ & 5.69 \\
\hline Overall (l-squared $<0.1 \%, P=0.546$ ) & $-0.03(-0.13,0.08)$ & 100.00 \\
\hline$T_{-1.41}^{1}$ & 41 & \\
\hline
\end{tabular}

Figure 3. Forest plot of vitamin D supplementation effect on insulin resistance. It was indicated that vitamin D supplementation had no significant effect on insulin resistance improvement in non-diabetics. SMD, standardized mean difference; 95\% CI, 95\% confidence interval. (a) and (b) indicate the first and second trial in the reference, respectively.

vitamin D supplementation compared with control was significantly decreased $(\mathrm{MD}=-1.99,95 \% \mathrm{CI}=-3.25,-0.73, \mathrm{P}=0.002$; Table II).

Effect of vitamin D supplementation on insulin resistance. A total of 13 studies $(8-10,12-15,18,33,34,39,41,43)$ containing
14 RCTs reported HOMA-IR results. There was no statistical heterogeneity between the studies $\left(\mathrm{I}^{2}<0.01 \%, \mathrm{P}=0.546\right)$. Therefore, the fixed effect model was applied for analysis of the results. The meta-analysis indicated that there were no statistically significant changes in HOMA-IR following vitamin $\mathrm{D}$ intervention compared with control $(\mathrm{SMD}=-0.03$, 
Table II. Results of subgroup and sensitivity analyses.

\begin{tabular}{|c|c|c|c|c|c|c|c|c|c|}
\hline \multirow[b]{2}{*}{ Subgroup } & \multicolumn{3}{|c|}{ RR } & \multicolumn{3}{|c|}{ FPG } & \multicolumn{3}{|c|}{ HOMA-IR } \\
\hline & $\mathrm{RR}$ & $95 \% \mathrm{CI}$ & P-value & MD & $95 \% \mathrm{CI}$ & P-value & SMD & $95 \% \mathrm{CI}$ & P-value \\
\hline \multicolumn{10}{|l|}{ Blood glucose state } \\
\hline Normal (<6.1 mmol/l) & - & - & - & 1.09 & $(-0.89,3.06)$ & 0.280 & -0.04 & $(-0.21,0.13)$ & 0.638 \\
\hline $\begin{array}{l}\text { Prediabetes or early } \\
\text { diabetes }(6.1-7.0 \mathrm{mmol} / \mathrm{l})\end{array}$ & 0.84 & $(0.70,1.00)$ & 0.047 & -3.40 & $(-6.64,-0.15)$ & 0.041 & -0.02 & $(-0.15,0.12)$ & 0.817 \\
\hline \multicolumn{10}{|l|}{ Age of subjects, years } \\
\hline$<45$ & - & - & - & -0.18 & $(-4.98,4.63)$ & 0.942 & -0.14 & $(-0.39,0.10)$ & 0.249 \\
\hline $45 \leq$ age $<60$ & 0.70 & $(0.41,1.20)$ & 0.195 & -3.02 & $(-8.38,2.35)$ & 0.271 & 0.04 & $(-0.13,0.21)$ & 0.646 \\
\hline$\geq 60$ & 0.90 & $(0.71,1.04)$ & 0.114 & -0.78 & $(-2.33,0.76)$ & 0.321 & -0.13 & $(-0.36,0.10)$ & 0.260 \\
\hline \multicolumn{10}{|l|}{ Mean BMI, kg/m² } \\
\hline$<25$ & - & - & - & -2.80 & $(-5.57,-0.03)$ & 0.048 & -0.02 & $(-0.46,0.41)$ & 0.917 \\
\hline $25 \leq \mathrm{BMI}<30$ & 0.82 & $(0.69,0.98)$ & 0.032 & -1.78 & $(-5.60,2.05)$ & 0.363 & -0.08 & $(-0.24,0.09)$ & 0.384 \\
\hline$\geq 30$ & 1.33 & $(0.45,3.92)$ & 0.611 & -1.07 & $(-2.58,0.44)$ & 0.164 & -0.03 & $(-0.21,0.15)$ & 0.770 \\
\hline \multicolumn{10}{|l|}{ Baseline 25(OH)D, ng/ml } \\
\hline$<20$ & 0.84 & $(0.70,1.00)$ & 0.055 & -1.51 & $(-6.17,3.16)$ & 0.527 & $<0.01$ & $(-0.13,0.14)$ & 0.949 \\
\hline $20 \leq 25(\mathrm{OH}) \mathrm{D}<30$ & 0.95 & $(0.68,1.33)$ & 0.758 & -1.99 & $(-3.25,-0.73)$ & 0.002 & -0.09 & $(-0.38,0.21)$ & 0.575 \\
\hline$\geq 30$ & - & - & - & -2.15 & $(-8.26,3.95)$ & 0.489 & -0.49 & $(-0.90,-0.07)$ & 0.021 \\
\hline \multicolumn{10}{|l|}{ Duration, months } \\
\hline$<12$ & - & - & - & -0.40 & $(-2.82,2.02)$ & 0.747 & -0.03 & $(-0.22,0.15)$ & 0.744 \\
\hline$\geq 12$ & 0.86 & $(0.74,1.01)$ & 0.072 & -2.53 & $(-5.83,-0.76)$ & 0.132 & -0.02 & $(-0.15,0.10)$ & 0.725 \\
\hline \multicolumn{10}{|l|}{ Dose, IU/day } \\
\hline$\leq 2,000$ & 0.95 & $(0.68,1.33)$ & 0.758 & -0.06 & $(-1.99,1.88)$ & 0.955 & -0.02 & $(-0.15,0.11)$ & 0.741 \\
\hline$>2,000$ & 0.84 & $(0.70,1.00)$ & 0.047 & -2.84 & $(-6.88,1.20)$ & 0.169 & -0.03 & $(-0.21,0.14)$ & 0.724 \\
\hline \multicolumn{10}{|l|}{ Intervention with calcium } \\
\hline Yes & 0.95 & $(0.68,1.33)$ & 0.758 & -1.07 & $(-3.23,1.10)$ & 0.334 & -0.06 & $(-0.25,0.13)$ & 0.553 \\
\hline No & 0.84 & $(0.70,1.00)$ & 0.047 & -1.70 & $(-4.58,1.18)$ & 0.247 & -0.01 & $(-0.14,0.11)$ & 0.859 \\
\hline $\begin{array}{l}\text { Sensitivity analysis } \\
\text { (excluding Jadad <4) }\end{array}$ & 0.87 & $(0.73,1.05)$ & 0.156 & -0.86 & $(-2.02,0.30)$ & 0.147 & -0.05 & $(-0.13,0.08)$ & 0.635 \\
\hline
\end{tabular}

RR, relative risk; FPG, fasting plasma glucose; HOMA-IR, homeostasis model insulin resistance index; BMI, body mass index; 95\% CI, 95\% confidence interval; MD, mean difference; SMD, standardized mean difference; 25(OH)D, 25-hydroxyvitamin D; -, no results.

$95 \% \mathrm{CI}=-0.13,0.08, \mathrm{P}=0.635$; Fig. 3$)$. In the subgroup of baseline $25(\mathrm{OH}) \mathrm{D}_{3}$ sufficiency $\left.[25(\mathrm{OH}) \mathrm{D} \geq 30 \mathrm{ng} / \mathrm{ml})\right]$, HOMA-IR following vitamin D supplementation was significantly lower than that of controls $(\mathrm{SMD}=-0.49,95 \% \mathrm{CI}=-0.90,-0.07$, $\mathrm{P}=0.021$; Table II).

Effect of vitamin D supplementation on T2DM prevention. A total of 6 studies $(11,13,17-19,38)$ containing 6 RCTs reported RR results. There was no statistical heterogeneity between the studies $\left(\mathrm{I}^{2}<0.01 \%, \mathrm{P}=0.448\right)$. Subsequently, the fixed effect model was used for analysis. The results suggested that there was no statistically significant difference in the incidence of T2DM following vitamin D intervention or control in the non-diabetic population $(\mathrm{RR}=0.86,95 \% \mathrm{CI}=0.74,1.01$, $\mathrm{P}=0.072$; Fig. 4). Subgroup results indicated that the incidence of T2DM decreased following intervention with vitamin D supplement dose $>2,000 \mathrm{IU} /$ day and in those with intervention without calcium $(\mathrm{RR}=0.84,95 \% \mathrm{CI}=0.70,1.00, \mathrm{P}=0.047$ and $\mathrm{RR}=0.84,95 \% \mathrm{CI}=0.70,1.00, \mathrm{P}=0.047$, respectively; Table II). In addition, the incidence rates of T2DM in pre-diabetic individuals and in overweight $(25 \leq \mathrm{BMI}<30)$ individuals were lower than that in controls $(\mathrm{RR}=0.84,95 \% \mathrm{CI}=0.70,1.00$,
$\mathrm{P}=0.047$ and $\mathrm{RR}=0.82,95 \% \mathrm{CI}=0.69,0.98, \mathrm{P}=0.032$, respectively; Table II).

Sensitivity analysis and publication bias. For each outcome variable, each study was excluded sequentially, and the results of the remaining studies were combined to determine the impact of the excluded study on the overall results. Additionally, following the exclusion of low-quality studies (Jadad score <4), heterogeneity analysis was conducted to determine the source of heterogeneity. For the incidence of T2DM and HOMA-IR, sensitivity analysis indicated that the results of meta-analysis prior to and following the exclusion of any one study were similar; however, the result of meta-analysis of FPG level following the exclusion of one study (11) differed markedly from that prior to its exclusion (data not shown). Following the exclusion of low quality studies $(11,12,17,18,33,35,40)$, the heterogeneity decreased $\left(\mathrm{I}^{2}=40.6 \%, \mathrm{P}=0.034\right.$; data not shown). It was hypothesized that literature quality may be a major source of heterogeneity; on meta-analysis, there were no significant differences between the effects of vitamin D intervention and control treatments on RR, FPG and HOMA-IR following the exclusion of the low-quality studies (Table II). 


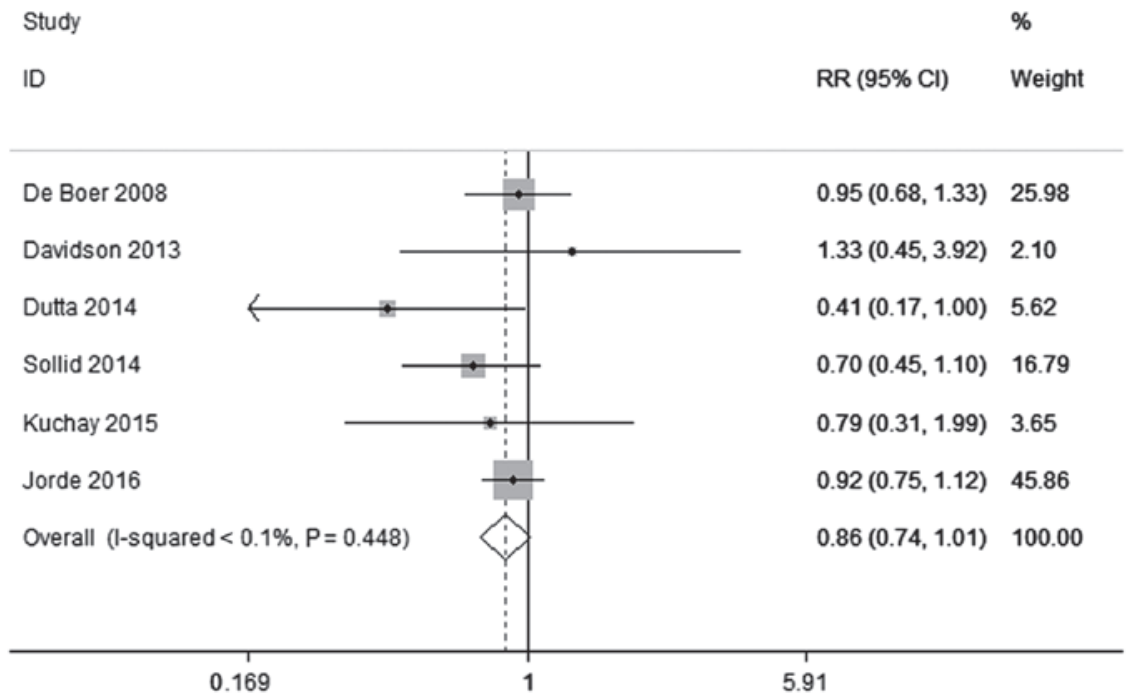

Figure 4. Forest plot of vitamin D supplementation effect on T2DM prevention. The pooled results revealed that vitamin D supplementation had no significant effect on T2DM prevention in the non-diabetic population. T2DM, type 2 diabetes mellitus; RR, relative risk; 95\% CI, $95 \%$ confidence interval.
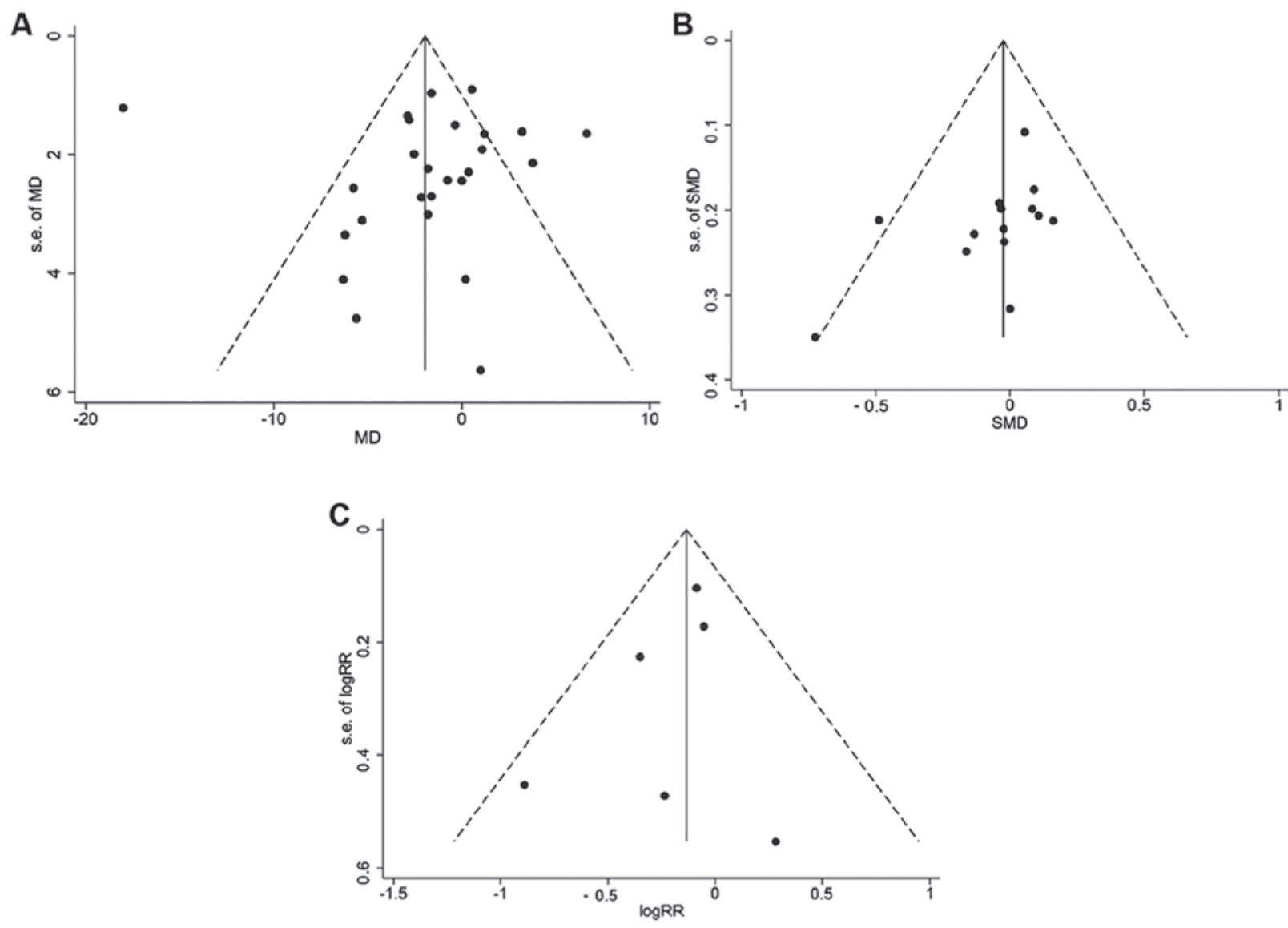

Figure 5. Funnel plots with pseudo 95\% confidence limits for (A) fasting plasma glucose (Begg's test: $\mathrm{P}=0.086$; Egger's test: $\mathrm{P}=0.800$ ), (B) insulin resistance (Begg's test: $\mathrm{P}=0.125$; Egger's test: $\mathrm{P}=0.080$ ) and $(\mathrm{C})$ type 2 diabetes mellitus prevention (Begg's test: $\mathrm{P}=1.00$; Egger's test; $\mathrm{P}=0.421$ ). s.e.; standard error; $\mathrm{MD}$, mean difference; SMD, standardized mean difference; RR, relative risk.

For each outcome variable, there was no obvious asymmetry in funnel plots (Fig. 5). Begg's and Egger's tests also indicated no significant publication bias for FPG (Begg's test: $\mathrm{P}=0.086$; Egger's test: $\mathrm{P}=0.800)$, insulin resistance (Begg's test: $\mathrm{P}=0.125$; Egger's test: $\mathrm{P}=0.080$ ) or $\mathrm{T} 2 \mathrm{DM}$ prevention (Begg's test: $\mathrm{P}=1.00$; Egger's test; $\mathrm{P}=0.421$ ).

\section{Discussion}

To the best of our knowledge, the present report is the first systematic meta-analysis of the effect of vitamin D supplementation on FPG, insulin resistance and prevention of T2DM with consideration of individual variation and intervention 
strategy in non-T2DM subjects. Although no significant effect was identified in the pooled meta-analysis, stratified analysis suggested that both individual variation and intervention strategy had influence on the supplementation effect of vitamin D. As T2DM has a delayed latency and is associated with a variety of pathogenic factors, the results of the subgroup analysis still have reference value.

Firstly, the baseline level of $25(\mathrm{OH}) \mathrm{D}$ is an important parameter to consider with vitamin D supplementation. A significant effect on insulin sensitivity improvement was only identified for individuals with baseline 25(OH)D levels higher than $30 \mathrm{ng} / \mathrm{ml}$; FPG was decreased significantly by supplementation with vitamin D in individuals with 25(OH)D levels between $20-30 \mathrm{ng} / \mathrm{ml}$; and vitamin D supplementation may prevent T2DM among individuals with 25(OH)D levels lower than $20 \mathrm{ng} / \mathrm{ml}$. Therefore, as the effect of vitamin D supplementation varied in individuals with different $25(\mathrm{OH}) \mathrm{D}$ levels, there should be consideration of baseline $25(\mathrm{OH}) \mathrm{D}$ level during vitamin $\mathrm{D}$ supplementation.

Secondly, obesity is a factor that requires consideration during vitamin D supplementation. No significant effect was identified in obese subjects (BMI $\geq 30$ ) on decreasing FPG, improving insulin sensitivity or preventing T2DM following vitamin D supplementation. By contrast, decreased FPG was achieved in healthy-weight subjects (BMI <25); and a T2DM preventative effect was identified in overweight subjects $(25 \leq \mathrm{BMI}<30)$. Therefore, obesity may influence the effect of vitamin D supplementation; vitamin D is a fat-soluble compound, and thus a high body fat level may limit vitamin D in exerting its functions (44). Therefore, how to conduct vitamin D supplementation in obese individuals requires further study.

Thirdly, blood glucose state is important to consider for T2DM prevention and FPG control during vitamin D supplementation. In the current meta-analysis, significant effects of vitamin D supplement were observed in prediabetes subjects with regards to preventing T2DM and controlling FPG, but not to improving insulin sensitivity. Therefore, preferred outcomes may only be obtained in individuals with impaired fasting glycaemia.

Fourthly, the supplementation dose of vitamin D had a marked effect on T2DM prevention: T2DM development was prevented by supplementation with high-dose vitamin D (>2,000 IU/day). Thus, higher doses of vitamin D were preferable for T2DM prevention. It has been reported that supplementation with high-dose vitamin $\mathrm{D}$ was required to increase vitamin $\mathrm{D}$ level to a normal range in individuals with vitamin D deficiency $(45,46)$. Thus, high-dose vitamin supplementation may be more effective to improve vitamin D level in vivo. However, the potential toxicity of vitamin $\mathrm{D}$ remains unclear, and supplementation with high-dose vitamin D requires caution.

Finally, vitamin D supplementation without $\mathrm{Ca}$ had a significant T2DM preventative effect. It is well known that vitamin D plays an important role in calcium homeostasis and bone metabolism. It has been reported that intake of vitamin $\mathrm{D}$ and $\mathrm{Ca}$ at the same time may improve the function of vitamin D (47). However, the results of the current study contradict these previous findings. Therefore, further comprehensive trials are required to verify the present results.
In conclusion, supplementation with vitamin D had differing effects on FPG control, insulin sensitivity improvement and T2DM prevention in different stratified populations. The strategy of vitamin D supplementation also influenced the outcomes. Therefore, future trials should focus on the effects of 25(OH)D baseline level, obesity, blood glucose state, supplementation dose and the presence or absence of $\mathrm{Ca}$ strengthening in the control of blood glucose and insulin resistance.

\section{Acknowledgements}

Not applicable.

\section{Funding}

The present study was supported by the National Natural Science Foundation of China (grant nos. 81703270, 81573151 and 81573243) and the Science and Technology Foundation for Innovation Talent of Henan Province (grant no. 154200510010).

\section{Availability of data and materials}

All data generated or analyzed during the study are included in this published article.

\section{Authors' contributions}

SH and ZZ were responsible for literature retrieving and data extraction. CW and YW performed the data analysis. SY and WL were responsible for the study design and writing of the manuscript.

\section{Ethics approval and consent to participate}

Not applicable.

\section{Consent for publication}

Not applicable.

\section{Competing interests}

The authors declare that they have no competing interests.

\section{References}

1. van Driel M and van Leeuwen JPTM: Vitamin D endocrinology of bone mineralization. Mol Cell Endocrinol 453: 46-51, 2017.

2. Bikle DD: Extraskeletal actions of vitamin D. Ann N Y Acad Sci 1376, 29-52, 2016.

3. Autier P, Boniol M, Pizot C and Mullie P: Vitamin D status and ill health: A systematic review. Lancet Diabetes Endocrinol 2: 76-89, 2014.

4. Wang H, Chen W, Li D, Yin X, Zhang X, Olsen N and Zheng SG: Vitamin D and chronic diseases. Aging Dis 8: 346-353, 2017.

5. Pannu PK, Piers LS, Soares MJ, Zhao Y and Ansari Z: Vitamin D status is inversely associated with markers of risk for type 2 diabetes: A population based study in Victoria, Australia. PLoS One 12: e0178825, 2017.

6. Lucato P, Solmi M, Maggi S, Bertocco A, Bano G, Trevisan C, Manzato E, Sergi G, Schofield P, Kouidrat Y, et al: Low vitamin D levels increase the risk of type 2 diabetes in older adults: A systematic review and meta-analysis. Maturitas 100: 8-15, 2017. 
7. Berridge MJ: Vitamin D deficiency and diabetes. Biochem J 474 1321-1332, 2017.

8. Belenchia AM, Tosh AK, Hillman LS and Peterson CA: Correcting vitamin D insufficiency improves insulin sensitivity in obese adolescents: A randomized controlled trial. Am J Clin Nutr 97: 774-781, 2013

9. Nagpal J, Pande JN and Bhartia A: A double-blind, randomized, placebo-controlled trial of the short-term effect of vitamin $\mathrm{D}_{3}$ supplementation on insulin sensitivity in apparently healthy, middle-aged, centrally obese men. Diabet Med 26: 19-27, 2009.

10. Pittas AG, Harris SS, Stark PC and Dawson-Hughes B: The effects of calcium and vitamin D supplementation on blood glucose and markers of inflammation in nondiabetic adults. Diabetes Care 30: 980-986, 2007.

11. Kuchay MS, Laway BA, Bashir MI, Wani AI, Misgar RA and Shah ZA: Effect of vitamin D supplementation on glycemic parameters and progression of prediabetes to diabetes: A 1-year, open-label randomized study. Indian J Endocrinol Metab 19: 387-392, 2015.

12. Iraj B, Aminorroaya A and Amini M: Does the intramuscular injection of vitamin D increase insulin resistance? J Res Pharm Pract 1: 60-65, 2012.

13. Davidson MB, Duran P, Lee ML and Friedman TC: High-dose vitamin $D$ supplementation in people with prediabetes and hypovitaminosis D. Diabetes Care 36: 260-266, 2013

14. Grimnes G, Figenschau Y, Almås B and Jorde R: Vitamin D, insulin secretion, sensitivity, and lipids: Results from a case-control study and a randomized controlled trial using hyperglycemic clamp technique. Diabetes 60: 2748-2757, 2011.

15. Jorde R, Sneve M, Torjesen P and Figenschau Y: No improvement in cardiovascular risk factors in overweight and obese subjects after supplementation with vitamin D3 for 1 year. J Intern Med 267: 462-472, 2010.

16. Moreira-Lucas TS, Duncan AM, Rabasa-Lhoret R, Vieth R, Gibbs AL, Badawi A and Wolever TM: Effect of vitamin D supplementation on oral glucose tolerance in individuals with low vitamin D status and increased risk for developing type 2 diabetes (EVIDENCE): A double-blind, randomized, placebocontrolled clinical trial. Diabetes Obes Metab 19: 133-141, 2017.

17. Dutta D, Mondal SA, Choudhuri S, Maisnam I, Hasanoor Reza AH, Bhattacharya B, Chowdhury S and Mukhopadhyay S: Vitamin-D supplementation in prediabetes reduced progression to type 2 diabetes and was associated with decreased insulin resistance and systemic inflammation: An open label randomized prospective study from Eastern India. Diabetes Res Clin Pract 103: e18-e23, 2014.

18. de Boer IH, Tinker LF, Connelly S, Curb JD, Howard BV, Kestenbaum B, Larson JC, Manson JE, Margolis KL, Siscovick DS and Weiss NS; Women's Health Initiative Investigators: Calcium plus vitamin D supplementation and the risk of incident diabetes in the Women's Health Initiative. Diabetes Care 31: 701-707, 2008

19. Jorde R, Sollid ST, Svartberg J, Schirmer H, Joakimsen RM, Njølstad I, Fuskevåg OM, Figenschau Y and Hutchinson MY: Vitamin D 20,000 IU per week for five years does not prevent progression from prediabetes to diabetes. J Clin Endocrinol Metab 101: 1647-1655, 2016.

20. Wu C, Qiu S, Zhu X and Li L: Vitamin D supplementation and glycemic control in type 2 diabetes patients: A systematic review and meta-analysis. Metabolism 73: 67-76, 2017

21. Lee CJ, Iyer G, Liu Y, Kalyani RR, Bamba N, Ligon CB, Varma S and Mathioudakis N: The effect of vitamin D supplementation on glucose metabolism in type 2 diabetes mellitus: A systematic review and meta-analysis of intervention studies. J Diabetes Complications 31: 1115-1126, 2017.

22. Akbari M, Moosazadeh M, Lankarani KB, Tabrizi R, Samimi M, Karamali M, Jamilian M, Kolahdooz F and Asemi Z: Correction: The effects of vitamin D supplementation on glucose metabolism and lipid profiles in patients with gestational diabetes: A systematic review and meta-analysis of randomized controlled trials. Horm Metab Res: Aug 2, 2017 (Epub ahead of print).

23. Jamka M, Woźniewicz M, Jeszka J, Mardas M, Bogdański P and Stelmach-Mardas M: The effect of vitamin D supplementation on insulin and glucose metabolism in overweight and obese individuals: Systematic review with meta-analysis. Sci Rep 5: 16142,2015

24. Kresevic DM, Denton JE, Burant CJ and Pallaki M: Racial difference in response to vitamin D supplementation. J Natl Med Assoc 107: 18-24, 2015.
25. Dasarathy J, Varghese R, Feldman A, Khiyami A, McCullough AJ and Dasarathy S: Patients with nonalcoholic fatty liver disease have a low response rate to vitamin D supplementation. J Nutr 147: 1938-1946, 2017.

26. American Diabetes Association: Diagnosis and classification of diabetes mellitus. Diabetes Care 33 (Suppl 1): S62-S69, 2010.

27. Higgins and JPT Green S (eds): Cochrane Handbook for Systematic Reviews of Interventions, version 5.1.0. The Cochrane Collaboration, p228, 2011.

28. Jadad AR, Moore RA, Carroll D, Jenkinson C, Reynolds DJ, Gavaghan DJ and McQuay HJ: Assessing the quality of reports of randomized clinical trials: is blinding necessary? Control Clin Trials 17: 1-12. 1996

29. Follmann D, Elliott P, Suh I and Cutler J: Variance imputation for overviews of clinical trials with continuous response. J Clin Epidemiol 45: 769-773, 1992.

30. Flegal KM, Kit BK, Orpana H and Graubard BI: Association of all-cause mortality with overweight and obesity using standard body mass index categories: A systematic review and meta-analysis. JAMA 309: 71-82, 2013.

31. Gallagher JC and Sai AJ: Vitamin D insufficiency, deficiency, and bone health. J Clin Endocrinol Metab 95: 2630-2633, 2010.

32. Jin ZC, Zhou XH and He J: Statistical methods for dealing with publication bias in meta-analysis. Stat Med 34: 343-360, 2015.

33. Salehpour A, Shidfar F, Hosseinpanah F, Vafa M, Razaghi M and Amiri F: Does vitamin $\mathrm{D}_{3}$ supplementation improve glucose homeostasis in overweight or obese women? A double-blind, randomized, placebo-controlled clinical trial. Diabet Med 30: 1477-1481, 2013

34. Oosterwerff MM, Eekhoff EM, Van Schoor NM, Boeke AJ, Nanayakkara P, Meijnen R, Knol DL, Kramer MH and Lips P: Effect of moderate-dose vitamin D supplementation on insulin sensitivity in vitamin D-deficient non-Western immigrants in the Netherlands: A randomized placebo-controlled trial. Am J Clin Nutr 100: 152-160, 2014.

35. Qi M, Song Y, Li J, Tian L, Wang L, Xie Y, Gup Y and Bao Y: Effect of vitamin D supplementation on postprandial glucose in the elder with vitamin D deficiency and impaired glucose tolerance. Chin J Mod Drug Appl 10: 196-197, 2016 (In Chinese).

36. Mitri J, Dawson-Hughes B, Hu FB and Pittas AG: Effects of vitamin D and calcium supplementation on pancreatic $\beta$ cell function, insulin sensitivity, and glycemia in adults at high risk of diabetes: The calcium and vitamin $\mathrm{D}$ for diabetes mellitus (CaDDM) randomized controlled trial. Am J Clin Nutr 94: 486-494, 2011.

37. Tuomainen TP, Virtanen JK, Voutilainen S, Nurmi T, Mursu J, de Mello VD, Schwab U, Hakumäki M, Pulkki K and Uusitupa M: Glucose metabolism effects of vitamin D in prediabetes: The VitDmet randomized placebo-controlled supplementation study. J Diabetes Res 2015: 672653, 2015.

38. Sollid ST, Hutchinson MY, Fuskevåg OM, Figenschau Y, Joakimsen RM, Schirmer H, Njølstad I, Svartberg J, Kamycheva E and Jorde R: No effect of high-dose vitamin D supplementation on glycemic status or cardiovascular risk factors in subjects with prediabetes. Diabetes Care 37: 2123-2131, 2014.

39. Harris SS, Pittas AG and Palermo NJ: A randomized, placebocontrolled trial of vitamin D supplementation to improve glycaemia in overweight and obese African Americans. Diabetes Obes Metab 14: 789-794, 2012.

40. Major GC, Alarie F, Doré J, Phouttama S and Tremblay A: Supplementation with calcium + vitamin D enhances the beneficial effect of weight loss on plasma lipid and lipoprotein concentrations. Am J Clin Nutr 85: 54-59, 2007.

41. Wood AD, Secombes KR, Thies F, Aucott L, Black AJ, Mavroeidi A, Simpson WG, Fraser WD, Reid DM and Macdonald HM: Vitamin D3 supplementation has no effect on conventional cardiovascular risk factors: A parallel-group, double-blind, placebo-controlled RCT. J Clin Endocrinol Metab 97: 3557-3568, 2012

42. Zittermann A, Frisch S, Berthold HK, Götting C, Kuhn J, Kleesiek K, Stehle P, Koertke H and Koerfer R: Vitamin D supplementation enhances the beneficial effects of weight loss on cardiovascular disease risk markers. Am J Clin Nutr 89: 1321-1327, 2009.

43. Sun X, Cao ZB, Tanisawa K, Ito T, Oshima S and Higuchi M: Vitamin D supplementation reduces insulin resistance in Japanese adults: A secondary analysis of a double-blind, randomized, placebo-controlled trial. Nutr Res 36: 1121-1129, 2016. 
44. Vimaleswaran KS, Berry DJ, Lu C, Tikkanen E, Pilz S, Hiraki LT, Cooper JD, Dastani Z, Li R, Houston DK, et al; Genetic Investigation of Anthropometric Traits-GIANT Consortium: Causal relationship between obesity and vitamin D status: Bi-directional Mendelian randomization analysis of multiple cohorts. PLoS Med 10: e1001383, 2013.

45. Gowda U, Ruwanpathirana T, Fong DP, Kaur A and Renzaho AM: Efficacy of high dose vitamin D supplementation in improving serum $25(\mathrm{OH}) \mathrm{D}$ among migrant and non migrant population: A retrospective study. BMC Health Serv Res 16: 579, 2016.
46. Yang Y, Li Z, Yan G, Jie Q and Rui C: Effect of different dose of vitamin D supplementation on preterm infants- an updated meta-analysis. J Matern Fetal Neonatal Med: Oct 5, 2017 (Epub ahead of print).

47. Pittas AG, Dawson-Hughes B, Li T, Van Dam RM, Willett WC, Manson JE and Hu FB: Vitamin D and calcium intake in relation to type 2 diabetes in women. Diabetes Care 29: 650-656, 2006. 